\title{
Epistemologia e concepção de ciência de George Berkeley
}

\section{Epistemology and scientific conception of George Berkeley}

\author{
Gabriel Chiarotti Sardi \\ Graduação em andamento em Filosofia (2016). Universidade Estadual de Londrina - UEL. Centro de \\ Letras e Ciências Humanas, Departamento de Filosofia. Londrina, PR - Brasil.
}

\section{Pedro Henrique Nogueira Pizzutti}

Graduação em Filosofia (2018). Universidade Estadual de Londrina - UEL. Centro de Letras e Ciências Humanas. Departamento de Filosofia. Londrina, PR - Brasil.

Resumo: O presente artigo tem como objetivo apresentar a epistemologia do filósofo empirista e idealista George Berkeley (1685 - 1753). A tese central da teoria do conhecimento de Berkeley é que todo o conhecimento humano é conhecimento de ideias e não de fatos, sendo que tais ideias têm sua origem unicamente nos sentidos e somente podemos ater-nos a elas. Por isso o autor defende a impossibilidade de se afirmar a existência das ideias abstratas e também da substância material como substrato das ideias na mente. Berkeley pretendia derrubar as teses céticas e ateias do seu tempo formulando assim um rico e penetrante sistema filosófico, com insights de psicologia da visão, filosofia da linguagem e filosofia da ciência. Seus argumentos merecem um estudo minucioso, pois além de seu valor histórico suas ideias influenciaram sobremaneira a filosofia posterior, como nos atesta David Hume, que o trata como grande inspiração ${ }^{1}$, além do fato de ter sido precursor de muitas ideias que permeiam a filosofia da ciência contemporânea e, em vista disso, este artigo também aborda a relevância de suas posições frente ao debate atual conhecido como realismo/antirrealismo científicos.

Palavras-chave: Epistemologia; George Berkeley; Imaterialismo; Anti-Abstracionismo; Antirrealismo científico.

\begin{abstract}
The present article have aims to present the epistemology of the empiricist and idealist philosopher George Berkeley (1685 - 1753). The central thesis of Berkeley's theory, of knowledge is that all human knowledge is knowledge of ideas and not of facts, and such ideas have their origin only in the senses and we can only stick to them. For this question the author defends the impossibility of affirming the existence of abstract ideas and also of material substance as substratum of ideas in the mind. Berkeley sought to overthrow the skeptical and atheistic theses of his time, thus formulating a rich and penetrating philosophical system with insights from vision psychology, language and philosophy of science. His arguments deserve careful study, for beyond his historical value his ideas have greatly influenced later philosophy, as David Hume attests to, which treats him as a great inspiration; in addition to the fact that it was the forerunner of many ideas that permeate the philosophy of science
\end{abstract}

\footnotetext{
${ }^{1}$ Cf. Hume, Investigação acerca do entendimento humano. Abril Cultural: 1999.
} 
contemporary and therefore, this article also addresses the relevance of their positions in the current debate known as scientific realism and antirealism.

Keywords: Epistemology; George Berkeley; Immaterialism; Anti-Abstracionism; Scientific-antirealism.

\section{1 - Introdução}

George Berkeley nasceu em Kilkenny - Irlanda - no ano de 1685, e aos 15 anos já ingressara no Trinity College de Dublin, onde estudou línguas, matemática, lógica, filosofia e os clássicos, demonstrando desde tenra idade uma inteligência acima da média e uma elevada piedade religiosa, que culminou em sua ordenação sacerdotal como ministro anglicano em 1710. Foi missionário nas Bahamas, onde tentou construir um Colégio para educar os nativos e os filhos dos imigrantes ${ }^{2}$. Seu nome é listado como integrante da grande tríade do empirismo britânico ao lado de John Locke e David Hume, sendo um dos mais brilhantes filósofos do período moderno. Seus interesses filosóficos incluíam "preocupações epistemológicas, metafísicas, de filosofia da ciência, de psicologia da visão, além de física, matemática, economia, medicina, política e moral" (CONTE, 2010, p. 7).

O cenário de seu tempo fora marcado pelas inovações na filosofia da natureza trazidas por Sir Isaac Newton e pelas influências das filosofias de Nicolas Malebranche e John Locke ${ }^{3}$. Berkeley se propôs a combater os livre-pensadores, o ateísmo e a irreligião, formulando um sistema filosófico que é ao mesmo tempo idealista e empirista (no sentido mais extremo que algum filósofo já chegou a alcançar), onde exclui a possibilidade de alegação da existência da matéria, das ideias abstratas e da ausência de Deus. Berkeley veio a falecer em Oxford em 1753 possuindo fama de renomado filósofo por toda a Europa, sendo posteriormente exaltado por David Hume como "grande filósofo" (HUME, 2005, p. 46) e por John Stuart Mill como um dos "maiores gênios da filosofia" (MILL, apud Woolhouse, 1988, p. 22).

Sua maior obra é o Tratado sobre os Princípios do Conhecimento Humano, mais popularmente conhecida somente como Princípios do Conhecimento Humano ${ }^{4}$ (Principles of Human Knowledge), publicada originalmente em 1710, onde Berkeley apresenta as teses centrais de sua epistemologia. Podemos dividir a referida obra em quatro teses centrais além da Introdução - que praticamente é um texto independente, com vida própria (SILVA, 2014, p. 150) -, onde o autor expõe uma síntese do problema das ideias abstratas, suas teses e argumentos para resolver tal aporia. Tais teses seriam: a) A tese de que nosso conhecimento do mundo é somente conhecimento de ideias dos sentidos (sensações) e que os objetos são coleções de ideias; b) O condicionamento da existência do ser das coisas é o seu ser percebido pelo sujeito (esse est percipi); c) A existência se resume em espíritos (sendo chamados ora de percipiente, sujeito ou ainda $e u$ ) e ideias - aqui se trava a argumentação contra a existência da matéria como substratum das coisas do mundo e uma crítica às qualidades primárias de John

\footnotetext{
${ }^{2}$ A cidade norte-americana de Berkeley, que sedia o Campus da University of California, leva seu nome em homenagem ao filósofo, que inclusive doou grande parte de sua biblioteca pessoal, ainda em vida, para a instituição que viria a se tornar tal Universidade (cf. STRATHERN, 2003, p. 38). Infelizmente, o projeto de Berkeley não obteve sucesso, pois o dinheiro que lhe fora prometido pelo Parlamento Inglês nunca foi entregue.

${ }^{3}$ Berkeley se propôs a debater com todos estes pensadores, dedicando muitas páginas de suas obras a examinar minuciosamente as teses de cada um deles, apontando problemas e possíveis soluções. Inclusive, chegou a debater pessoalmente com Malebranche poucos dias antes da morte deste, criando-se até um boato de que Berkeley fora parcialmente culpado pela morte do filósofo, pois passaram toda uma tarde em um debate animado e acalorado, piorando o estado de saúde de Nicolas, que naquela altura sofria de uma grave doença pulmonar. Um relato da existência deste boato pode ser encontrado em Berkeley em 90 minutos de Paul Strathern, Zahar Editora: 2003; mas também há estudiosos que buscam desmentir essa história.

${ }^{4}$ Doravante vamos nos utilizar da sigla $\mathrm{PCH}$ para nos referirmos à obra supracitada.
} 
Locke; e finalmente, d) A necessária e indubitável existência do Espírito Supremo, ou seja, Deus.

Nas primeiras seções deste artigo vamos analisar os problemas e argumentos levantados pelo filósofo britânico nesta sua grande obra que veio a tornar-se um precioso clássico da Filosofia Ocidental, para em seguida realizarmos um breve apanhado crítico da sustentação de suas teses e as implicações para a ciência, fazendo um paralelo então com outra obra de sua autoria, a De Motu - na qual ele trata especificamente da mecânica newtoniana e busca corrigir seus erros epistemológicos oriundos de interpretações realistas. Esta obra de Berkeley desempenha um papel importante para a filosofia da ciência, sobretudo porque o filósofo praticamente antecipou em mais de 250 anos o debate que ficou conhecido como realismo e antirrealismo científicos, e sustentou pioneiramente teses que só voltaram a tomar forma no séc. XX.

No mais, para que suas teses de teoria do conhecimento fossem conhecidas também por uma maior parcela da população (esta que nem sempre era familiarizada com o estilo de escrita característico da filosofia - um tanto denso, complexo), Berkeley publicou em 1713 os Três Diálogos entre Hylas e Philonous, uma série de diálogos literários ricamente elaborados entre dois personagens onde são expostas as mesmas teses do PCH, porém de forma mais acessível e de fácil compreensão. Outras obras de destaque são seus dois tratados acerca da teoria da visão: Um ensaio para uma nova teoria da visão e A teoria da visão confirmada e explicada, onde o filósofo trata de epistemologia (porém de forma mais rudimentar do que no $\mathrm{PCH}$ ) e psicologia da visão, apresentando diversos experimentos mentais; também podemos citar o texto Siris, onde ele aborda inclusive assuntos da Química de seu tempo e também $O$ Analista, onde Berkeley trata de filosofia e matemática.

\section{2 - Conhecimento de sensações, anti-abstracionismo, nominalismo e imaterialismo}

Berkeley inicia sua obra alegando que tudo que possuímos em nossa mente são ideias (inclusive as sensações, sentimentos, etc.) e que a única origem possível de tais ideias são os órgãos dos sentidos que captam, de diferentes formas, diferentes ideias, despertando em nosso espírito sentimentos diversos. Nossa mente possui a capacidade cognitiva de combinar essas ideias, formando assim um objeto que em si é sempre particular (porque as ideias são sempre ideias particulares), mas dado o hábito de frequência com o qual nós combinamos determinadas ideias, criamos assim uma ideia geral através da linguagem que generaliza essa combinação, chamada de coleção de ideias, denominando então um objeto:

Por meio da visão tenho as ideias da luz e das cores em seus diversos graus e variações. Por meio do tato percebo, por exemplo, duro e macio, calor e frio, movimento e resistência e, de todos esses, a diferença em relação à quantidade ou ao grau. O olfato proporciona-me odores; o paladar, sabores; o ouvido leva à mente sons em toda a sua variedade de tom e de composição. E, quando se observa que várias dessas ideias se apresentam simultaneamente, elas passam a ser designadas por um nome e, dessa forma, a ser consideradas uma coisa. Assim, por exemplo, quando se observa que determinada cor, um sabor, um cheiro, uma figura e consistência estão juntos, são considerados uma coisa diferente, significada pelo nome maçã. Outras coleções de ideias constituem uma pedra, uma árvore, um livro; e as demais coisas sensíveis, sejam elas agradáveis ou desagradáveis, suscitam as paixões do amor, do ódio, da alegria, da tristeza e assim por diante. ( $\mathrm{PCH}, \S 1$, pp. 57-58)

Através desta perspectiva empirista-idealista, a qual alega que devemos nos ater somente às sensações (ideias) que nos foram concedidas pelos sentidos, Berkeley busca refutar a tese da existência das ideias abstratas, que conforme veremos pode conduzir à adoção da tese materialista do Universo, o que pode acarretar problemas teológicos. 
Crer em ideias abstratas é um grave erro, pois são ilusões perigosas que conduzem a uma ontologização de entidades que estão além dos nossos sentidos, portanto cuja existência não pode ser inferida. "Abstrair" uma ideia seria, segundo Berkeley, tentar elevar uma ideia singular a uma categoria absoluta além da dependência da experiência, porém nós nunca temos uma experiência empírica com uma ideia absoluta ou abstrata, mas somente com ideias particulares. Vale salientar que há uma grande diferença entre existir uma ideia geral (que remete a ideias particulares que compartilham de semelhanças) construída linguisticamente para fins de comunicação e compreensão, e a existência ontológica de uma ideia abstrata que se encontra além da experiência.

$\mathrm{O}$ autor nos fala na passagem supracitada acima $(\mathrm{PCH}, \S 1)$ que um conjunto de ideias singulares, tais como vermelha, redonda, macia, etc., pode formar uma ideia geral, que no caso é a ideia de maçã, mas que não podemos pensar uma ideia, tal como a cor vermelha separada do objeto que seja vermelho, como a maçã. Isso porque quando a nossa mente se remete à cor vermelha, ela nunca consegue separá-la de algo que seja vermelho, mesmo que seja um simples quadrado ou círculo imaginário. Vamos esquematizar tal exemplo:

A) Através dos nossos sentidos nós obtemos a ideia de uma "maçã", que é composta por uma coleção de ideias (vermelha, redonda, doce e macia);

B) Após a experiência empírica da visão sobre a maçã nós podemos ter a ideia do que é a cor vermelha;

C) Não podemos, entretanto, em hipótese alguma, inferir a existência da ideia abstrata "cor vermelha", pois só temos noção de tal cor através da ideia da maçã e ir além disso é ir além dos sentidos, pois ninguém experimentou a cor vermelha separada da maçã.

Esta é uma forma de nominalismo filosófico bem acentuada, pois em suma: só conhecemos ideias cuja origem se encontra nos sentidos e tais ideias são sempre e unicamente particulares e individuais. Consequentemente, a tese lockiana da abstração é um equívoco, pois gera uma falsa noção de que existem substâncias ou essências para além das nossas percepções que são substratos das ideias. Como visto, estamos limitados à percepção de sensações e não podemos inferir um substrato para sua origem além da nossa experiência, porquanto tudo o que habita nosso espírito/ mente são essas ideias/sensações, só podemos assemelhar uma ideia a outra ideia, e a causa da existência de uma ideia é unicamente o seu ser percebida.

Entre os homens prevalece a opinião singular de que as casas, montanhas, rios, todos os objetos sensíveis têm uma existência natural ou real, distinta da sua perceptibilidade pelo espírito. Mas, por mais segura aquiescência que este princípio tenha tido no mundo, quem tiver coragem de discuti-la compreenderá, se não me engano, que envolve manifesta contradição. Pois que são os objetos mencionados senão coisas percebidas pelos sentidos? E que percebemos nós além das nossas próprias ideias ou sensações? E não repugna admitir que alguma ou um conjunto delas possa existir impercebido? Se bem examinarmos esta asserção acharemos talvez que depende afinal da doutrina das ideias abstratas. Pode haver maior esforço de abstração do que separar a existência dos objetos sensíveis do fato de serem percebidos, assim como concebê-los existentes e impercebidos? Luz e cores, calor e frio, extensão e figuras, numa palavra, as coisas que vemos e sentimos, que são senão sensações, noções, ideias ou impressões nos sentidos? É possível separar alguma delas da percepção, mesmo em pensamento? Quanto a mim, o mesmo é separar uma coisa de si mesma. (BERKELEY, 2010, pp. 59-60, grifo nosso)

Para Berkeley, a grande causa da crença na existência da matéria é a errônea distinção entre qualidades primárias e qualidades secundárias, tal como postularam Galileo Galilei e John Locke. Por qualidades primárias subtendam-se atributos tais como extensão, forma, repouso, solidez, número; tais qualidades existiriam independentemente 
da nossa percepção, num substrato que seria a matéria. As qualidades secundárias comportariam outros atributos, mas estes existiriam somente na mente humana, como: sabor, cor, cheiro, som, etc. (BERKELEY, 2010, p. 62). O problema, segundo Berkeley, é aquele já explanado anteriormente: alegar a existência de uma entidade como independente é dar um salto inferencial indevido para além da experiência que é nossa única fonte de conhecimento (Ibidem, pp. 62-63). Claramente é notável que a posição da distinção de qualidades é refutada por duas teses de Berkeley, as quais possuem uma ligação intrínseca: a) nosso conhecimento é unicamente conhecimento de sensações dos sentidos, e b) a impossibilidade de abstração.

Se a tese da distinção das qualidades primárias e secundárias fora refutada, ruiu juntamente com ela a tese da existência da matéria como substrato das ideias do mundo, pois é inviável a afirmação que diz que a matéria existe e sustenta os acidentes, dado que isso seria uma afirmação nonsense, sendo que pela "matéria" buscava-se atribuir um substrato que não é comunicável à percepção (Ibidem, p. 67). Até este ponto o filósofo demonstrou com solidez seus argumentos acerca do imaterialismo e do anti-abstracionismo, mas sua teoria epistemológica ainda possui outros conceitos que devem ser examinados para completar lacunas. Vamos abordar conceitos como "espírito", "Deus" e sua famosa máxima "ser é ser percebido" (esse est percipi) nas seções que se seguem.

\title{
3 - O Espírito Percipiente, O Esse est Percipi, Deus e as Leis da Natureza
}

Além da existência das ideias que se apresentam aos nossos sentidos, há também outra categoria de ser que conhece ou percebe essas ideias e desempenha outras operações, tais como: imaginar, recordar e querer (BERKELEY, 2010, p. 58). A essa outra categoria de ser, Berkeley chama de diversos nomes, a saber, "eu", "espírito", "mente" e "alma", e a classifica como diversamente distinta da categoria das ideias dos sentidos, tratando-se de uma substância simples e indivisível. Aquilo que não pode ser representado por nenhuma ideia é o espírito humano, o qual enquanto percebe ideias é intelecto e enquanto produz ideias é vontade.

Portanto a mente não é uma ideia, porque seria inconcebível uma ideia existir em outra ideia, além de não ser representável por nenhuma outra, tratando-se de um agente. Neste sentido, a existência de uma ideia depende de ser percebida por uma mente. Berkeley visa a sustentar essa sua tese de peso com uma análise semântica do termo existir.

\begin{abstract}
Qualquer um pode ter disto conhecimento intuitivo se notar o sentido do termo "existir", aplicado a coisas sensíveis. Digo que existe a mesa onde escrevo - quer dizer, vejo-a e sinto-a; e se estiver fora do meu gabinete digo que ela existe, significando assim que se lá estivesse vê-la-ia, ou que outro espírito atualmente a vê. Houve um odor, isto é, cheirava alguma coisa; houve um som, isto é, ouviu-se algo; uma cor ou uma forma, isto é, foi percebida pela vista ou pelo tato. É tudo o que posso entender por esta e outras expressões. O que se tem dito da existência absoluta de coisas impensáveis sem alguma relação com o seu serpercebidas parece perfeitamente ininteligível. O seu ser é serem percebidas; nem é possível terem existência fora dos espíritos ou coisas pensantes que os percebem. (Ibidem, p. 59)
\end{abstract}

Através de seu empirismo extremo, Berkeley traça um limite para aquilo que nós podemos dizer que existe: só podemos deduzir a existência daquilo que nos foi sensível. Se tudo que existe são ideias e elas só podem existir se forem experenciadas em alguma mente, logo, o ser das coisas está condicionado ao seu ser percebido. Isto para o autor é uma verdade óbvia, enunciada logo no início da Introdução do PCH.

Mas como distinguir entre as ideias criadas pela nossa imaginação e as que não podemos modificar pela vontade? Essa última classe de ideias são mais "vivas, 
fortes, vivazes, ordenadas e coerentes" (Ibidem, p. 78), são criações de um outro espírito superior e sábio, que percebe todas as ideias existentes a todo momento e as reproduz a nós: este espírito é Deus. Quando acordamos pela manhã, não depende da nossa vontade enxergar a luz do dia, mas estamos determinadamente condicionados a experimentá-la, portanto algum Espírito Superior produziu tal ideia.

Deus salva o ordenamento da epistemologia de Berkeley, pois é através dele que podemos confiar que o mundo não vai desaparecer quando fecharmos os olhos (pois Ele o percebe constantemente), além de manter uma estabilidade constante das ideias, é o que o filósofo chama de leis da natureza. As leis da natureza são leis fixas, métodos de que a Mente Superior se utiliza para transmitir ideias aos nossos sentidos, e é graças a elas que podemos estabelecer certa regularidade dos fenômenos do mundo e planejar nossa vida. Esse funcionamento uniforme e coerente é dirigido para a conservação da nossa vida, e assim pode revelar-nos toda a bondade e sabedoria de Deus (Ibidem, 2010, p. 161).

Berkeley finaliza sua obra com uma exortação para que ninguém altere seu modo de vida, sua visão de mundo no tocante à realidade, devido à exposição de sua teoria do conhecimento, pois o único erro que deve ser extirpado é a crença da substância material, e seu abandono não implica nenhuma mudança radical no que conhecemos nem empobrece a vida.

\section{4 - O problema abordado no De Motu}

A obra "De Motu: Sive de motus principio E natura et de causa" (ou conhecida somente como "Sobre o Movimento") foi publicada originalmente em 1721 e expressa o interesse do autor por questões científicas. Neste trabalho, o problema central é uma análise do movimento - princípio, natureza e causa de comunicação - (SILVA, 2006, p. 101), por conta do sucesso da mecânica newtoniana; é quando Berkeley rejeita noções como espaço, movimento e tempo absolutos, concedendo uma abordagem instrumentalista de tais conceitos científicos (CONTE, 2010, p. 24; SILVA, 2014, p. 150) e tenta resolver a aporia das qualidades ocultas ${ }^{5}$.

Isaac Newton obteve grande sucesso com seus trabalhos relativos à mecânica e seus feitos foram, inclusive, admirados em grande escala pelo próprio Berkeley (cf. SILVA, 2014, p. 152). Porém, Newton postulou qualidades ocultas (entidades inobserváveis ${ }^{6}$ ) como peças fundamentais de sua teoria, tais como força, gravidade e velocidade, o que se apresentava então como problema para a epistemologia empirista e anti-abstracionista de Berkeley caso se partisse de uma interpretação que considerasse tais qualidades como entes reais e independentes, pois elas não podem ser empiricamente experimentadas.

\footnotetext{
${ }^{5}$ Esse problema é conhecido na atualidade como "problema das entidades inobserváveis". Entidades observáveis são os componentes de uma teoria científica passíveis de observação empírica. Ex.: luas de Júpiter. Entidades inobserváveis são os componentes de uma teoria científica que não são passíveis de observação empírica, mas são postulados por desempenhar um papel-chave dentro da rede conceitual da teoria, permitindo que esta seja bem-sucedida. Ex.: elétrons.

${ }^{6} \mathrm{O}$ grande filósofo da ciência holandês Bas van Fraassen nos dá um exemplo da distinção entre entidades observáveis e inobserváveis em teorias científicas. O filósofo busca explicitar que, a seu ver, entidades empiricamente percebidas através de instrumentos tecnológicos não devem ser tidas como entidades inobserváveis. Vejamos: "Dar uma olhada nas luas de Júpiter através de um telescópio me parece ser uma caso claro de observação, uma vez que, sem dúvida, os astronautas vão ser capazes de vê-las também de perto. Mas a suposta observação de micropartículas em uma câmara de vapor me parece um caso claramente diferente se estiver correta nossa teoria sobre o que ali acontece. A teoria diz que se uma partícula carregada atravessa uma câmara preenchida com vapor saturado, alguns átomos nas vizinhanças de sua trajetória são ionizados. Se esse vapor é descomprimido e, portanto, se se torna supersaturado, ele condensa em gotículas onde estão os íons, criando assim a trajetória da partícula" (VAN FRAASSEN, 2007, p. 41).
} 
Como vimos anteriormente, Berkeley adotou um empirismo extremo no qual somente entes empiricamente verificáveis são dotados de significado, pois apenas possui significado aquilo que tem referencial nas ideias obtidas pelos sentidos. Logo, o que está além da experiência, tais como as qualidades ocultas, não se configuram como ideias, portanto não passam de termos vazios, destituídos de significado. A intenção de Berkeley nesta obra é descobrir a causa ou princípio do movimento, portanto o filósofo objeta que o conceito velocidade seja atribuído como a causa, pois neste caso ele estaria sendo interpretado como uma ideia abstrata, um ente externo e isolado a um corpo, independente de outros processos como tempo e espaço; portanto inacessível à experiência sensível, tratando-se então de uma qualidade oculta, um termo destituído de significado, segundo o autor.

Berkeley alega no $\$ 9$ do De Motu que o problema é a interpretação abstrata dos termos da mecânica newtoniana, pois isso implicaria uma concepção na qual eles seriam compreendidos isoladamente como se denotassem processos isolados, como, por exemplo, o conceito velocidade, que é em si uma qualidade oculta (SILVA, 2006, p. 106). Afirmar que uma qualidade oculta é o princípio de um fenômeno é o mesmo que afirmar que uma ideia abstrata é o princípio de uma ideia; porém ideias abstratas não existem, pois não são percebidas de forma empírico-cognitiva.

Quando suportamos corpos pesados, experimentamos o esforço, o cansaço e o desconforto. Percebemos também, nos corpos pesados em queda, um movimento acelerado em direção ao centro da Terra; e isso é tudo o que os sentidos nos informam. Contudo, inferimos pela razão que existe alguma causa ou princípio desses fenômenos, e esse princípio é popularmente denominado gravidade. Porém, uma vez que a causa da queda dos corpos pesados não pode ser vista nem conhecida, a gravidade não pode ser apropriadamente denominada, nesse sentido, uma qualidade sensível. Portanto, é uma qualidade oculta. Mas dificilmente poderíamos conceber o que é uma qualidade oculta ou como qualquer qualidade pode agir ou executar qualquer coisa - de fato, não podemos conceber. (BERKELEY, 2006, p. 2)

Berkeley então, para não descartar a mecânica de Newton, concede uma nova interpretação a tais conceitos partindo de uma abordagem instrumentalista e relacional deles dentro da teoria científica (holismo). Tais momentos serão analisados separadamente para facilitar a compreensão das duas críticas distintas.

\section{5 - Instrumentalismo}

Sob a ótica de seu Instrumentalismo, o filósofo não exclui as qualidades ocultas, ao invés disso, ele as considera como criações fictícias, hipóteses matemáticas ${ }^{7}$ úteis, ou seja, instrumentos para a previsão de fenômenos; daí vem a origem do termo: instrumentalismo.

Força, gravidade, atração e termos desse tipo são úteis para o raciocínio e o cálculo sobre o movimento e sobre os corpos em movimento, mas não para o entendimento da natureza simples do próprio movimento ou para enunciar tantas qualidades distintas. Com efeito, a atração não foi introduzida por Newton como uma qualidade física, verdadeira, mas apenas como uma hipótese matemática. (Ibidem, p. 5)

Mesmo que as qualidades ocultas não possam ser inferidas como reais (portanto como causas de fenômenos) devido à ausência de significação por falta de correspondente empírico, elas possuem uma serventia útil ao completar lacunas de que a observação empírica não deu conta na teoria. Deste modo, a teoria científica não explica como o

\footnotetext{
${ }^{7}$ Vale ressaltar que o autor não considera os entes matemáticos (tais como números) dotados de realidade, mas sim dependentes do seu artífice (cf. SILVA, 2004, p. 2).
} 
mundo é, mas ajuda a prever fenômenos. Logo, tanto a teoria quanto as qualidades ocultas são apenas instrumentos.

Mas ainda assim alguém poderia objetar: "seria realmente sensato considerar uma teoria científica bem-sucedida somente como um instrumento e não como uma explicação real do mundo?". Devemos, primeiramente, distinguir um fator importante: as teorias científicas muitas vezes se propõem a solucionar problemas empíricos (não somente este tipo de problema, pois muitas vezes as discussões se travam por causa de problemas conceituais) e não a explicar simples fenômenos ${ }^{8}$. Portanto, as teorias são respostas a tais questões e não necessitam serem verdadeiras para responderem de forma satisfatória. O filósofo da ciência Larry Laudan, em sua obra O progresso e seus problemas (1977), nos exemplifica este ponto ao citar a questão das teorias de queda dos corpos de Galileu e de Newton. Ambas as teorias solucionam satisfatoriamente o problema (como o próprio Newton afirmou), porém são formalmente incompatíveis. Neste caso, surge o problema de definir um padrão de explicação e atribuí-lo para uma das teorias, valendo-se aliás do fato de que sempre as teorias são substituídas por outras sucessivamente.

Outra característica interessante da proposta instrumentalista de Berkeley é que o sentido "fictício" das qualidades ocultas fica sujeito à rede conceitual do cientista, pois elas são hipóteses que servem como meios de elucidação e previsão de fenômenos, e tentar garantir sua existência real e externa à teoria é um salto que pode conduzir inevitavelmente ao fracasso, já que novas teorias alternativas podem surgir e desconsiderar tais entes inobserváveis, ou, ainda, conceder um novo significado ao termo. Podemos ilustrar isso com um breve incurso na história da química. Tomemos, por exemplo, o conceito de "óxido" presente na teoria flogística - os óxidos eram componentes dos metais -; com a revolução paradigmática operada pela teoria do oxigênio de Lavoisier, o termo "óxido" passou a significar uma combinação entre oxigênio e metais (cf. THAGARD, 1990, p. 184).

Essa noção está intrinsicamente relacionada com a segunda crítica que veremos logo adiante.

\section{6 - Holismo Conceitual}

Para compreendermos essa crítica, precisamos, primeiramente, retomarmos o exemplo anti-abstracionista da maçã contido no PCH: não podemos separar as ideias que compõem a ideia geral de maçã e tomá-las como existentes per si. Aqui a crítica de Berkeley toma uma nova postura, pois negar significação a um termo por ausência de referência empírica é um ponto; já negar significação por ausência de correlação com outros processos (abstração) é uma crítica diferente que se aplica tanto ao observável quanto ao inobservável. São dois os parágrafos do De Motu onde o autor expressa sua posição, sendo eles respectivamente o $\$ 11$ e o $\S 43$ :

A força de gravitação não deve ser separada do momento (momento); mas o momento não existe sem velocidade, pois a massa é multiplicada pela velocidade; além disso, a velocidade não pode ser compreendida sem o movimento e, portanto, o mesmo se aplica à força de gravitação. Desse modo, nenhuma força torna-se por si mesma cognoscível, exceto pela ação, e é por esta última que a força é medida; mas não somos capazes de separar a ação de um corpo de seu movimento. (BERKELEY, 2006, p. 4)

\footnotetext{
${ }^{8}$ Um fenômeno pode se tornar um problema empírico, mas para isso a comunidade científica deve estar de acordo com sua relevância (LAUDAN, 2010, p. 22).
} 
O movimento nunca se apresenta aos sentidos separado da massa corpórea, do espaço e do tempo. Existem aqueles que desejam considerar o movimento como uma ideia simples e abstrata, separada de todas as outras coisas. (Ibidem, p. 13)

Do mesmo modo que a ideia "cor vermelha" não pode existir separada da coleção de ideias que forma a ideia geral "maçã", uma qualidade como "gravidade" não pode ser pensada como independente de outras ideias correlacionadas, tais como a ideia de "momento", que está relacionada com "velocidade", que por sua vez está ligada à "massa", que se segue de "espaço" e "tempo". Deste modo, tratar uma qualidade como independente e isolada (abstraída) de outros processos e qualidades é retirar seu significado, que está subordinado à rede conceitual da teoria, portanto é impossível considerá-la como causa de algum fenômeno.

\begin{abstract}
Assim, aplicando-se o anti-abstracionismo de Berkeley ao conceito de "gravidade", o problema não se localizaria na falta de referência empírica do conceito, mas em sua natureza abstrata; ou seja: em sua ausência de relação com outros termos da mecânica. [...] E, deste modo, não é exatamente o caso de se rejeitar o conceito de "força" ou de "gravidade", mas de utilizá-lo como se utiliza o conceito de "cor", pois como cor é sempre a cor de um corpo extenso, a gravidade também deveria ser interpretada como uma qualidade associada a outras qualidades. (SILVA, 2014, p. 10)
\end{abstract}

Em suma, qualidades ocultas são entes não disponíveis à inspeção empírica, termos abstratos utilizados em teorias científicas para completar lacunas ou expressar generalizações. Porém sua existência não pode ser inferida, pois o conhecimento válido se refere somente àquele disponível aos nossos sentidos e tais qualidades só possuem significado quando relacionadas a outros conceitos (holismo conceitual), pois sozinhas não possuem sentido algum. Não obstante, são instrumentos úteis para o entendimento e previsão de fenômenos (instrumentalismo), portanto podem ser mantidas desde que se tenha a clara noção da distinção entre qualidades reais e ocultas.

\title{
7 - Consequências para o Realismo Científico
}

Para compreendermos as teses do realismo científico, devemos primeiramente possuir uma breve noção do que são as teorias científicas. As teorias científicas são produtos de uma atividade humana denominada prática científica. Tal atividade possui motivações externas variadas, tais como econômicas, políticas, militares, etc.; mas seu objetivo interno, intrínseco, é a formulação de explicações consistentes das causas de fenômenos, bem como a de meios para prevê-los, como nos atesta o filósofo da ciência realista Michel Ghins:

A atividade científica caracteriza-se pela busca de metas específicas, entre as quais a capacidade de predizer fenômenos e de explicá-los. Para os filósofos da ciência, assim como para os cientistas, essa é uma das suas metas prioritárias, de tal modo que as teorias científicas são elaboradas com a finalidade de predizer o comportamento dos fenômenos ao longo do tempo e de compreender suas causas. (GHINS, 2013, p. 15)

Realismo científico é a posição filosófica que assume o pressuposto de que as nossas melhores teorias científicas "nos dizem como o mundo é, tanto em seus aspectos observáveis quanto inobserváveis" (FRENCH, 2009, p. 92). Ou seja, para o realista científico, as teorias não são somente instrumentos de previsões ou possiblidades alternativas de explicação de fenômenos com suas entidades inobserváveis, mas sim a verdade acerca de tais fenômenos no mundo, independente da nossa capacidade de descobri-los. Ainda, de acordo com French: 
Como acabamos de indicar, de acordo com o "realista", as teorias científicas descrevem corretamente como o mundo é, isto é, as teorias científicas: A) são verdadeiras; B) descrevem corretamente que tipos de coisas há no mundo (observáveis e inobserváveis); C) descrevem corretamente a maneira como essas coisas estão relacionadas. (FRENCH, 2009, p. 94)

A postura de Berkeley invalida os três pontos elencados acima, pois de acordo com sua posição antirrealista: (A) não podemos afirmar que as teorias científicas são verdadeiras, ao menos em sua totalidade, pois muitas vezes pressupõem qualidades ocultas; (B) estas não podem ser inferidas como verdadeiras ou falsas, por se encontrarem além da experiência e seu significado sujeito a uma rede conceitual (C) que pode sofrer diversas alterações para a adequação fenômeno-teoria.

Deste modo, as teorias científicas, bem como os entes inobserváveis, não dizem como o mundo é e são somente instrumentos para análise e previsão de fenômenos, o que se afasta da perspectiva que o realista possui acerca da ciência.

\section{Conclusão}

O legado de Berkeley possui grande importância e atualmente está sendo redescoberto por uma série de autores e estudiosos da filosofia. No século passado, o próprio Bertrand Russell ao escrever sobre o bispo em sua História da Filosofia Ocidental nos diz que Berkeley foi um engenhoso filósofo e um dos poucos que chegou a elaborar um argumento ponderável sobre a existência de Deus ${ }^{9}$.

Infelizmente por alguns fatores, Berkeley teve sua importância ofuscada nos círculos acadêmicos por um determinado tempo. Em parte, pela crítica kantiana de que ele se tratava de um filósofo dogmático que negava a possibilidade de espaço e que tal posição idealista fora refutada na Estética Transcendental (cf. KANT, 2001, p. 243), embora, na Crítica da Razão Pura, Kant também adote uma posição semelhante à de Berkeley ${ }^{10}$.

Outro fator que levou a uma injusta desconsideração de Berkeley foi sua posição antirrealista da ciência, conforme exposta no trabalho, que na primeira metade do séc. XX desagradou alguns positivistas lógicos e racionalistas críticos (que ainda carregavam em suas teses um pouco de cientificismo realista do séc. XIX), tratando o filósofo como talvez um "mau filósofo da ciência" e desconsiderando seus brilhantes insights e sua grande influência sobre David Hume, com quem se propuseram dialogar ${ }^{11}$. Mas, conforme visto, tal posição vem mudando atualmente e parte disto se dá graças ao avanço do programa historiográfico iniciado por Kuhn e pelo socioconstrutivismo de David Bloor e Bruno Latour.

No entanto, algumas posições de Berkeley realmente enfrentam sérios problemas na contemporaneidade, por exemplo, seu instrumentalismo não consegue responder à predição de novos fatos por uma teoria vigente (SILVA, 2006, p. 113). Outro problema se dá no âmbito da filosofia da linguagem, pois Berkeley vai em contramão

\footnotetext{
${ }^{9}$ Podemos ainda encontrar na obra de Russell um verso do famoso escritor inglês Ronald Know, fazendo uma apologia às teses de Berkeley (cf. RUSSELL, 1957, p. 559).

${ }^{10}$ Afirmamos pois a realidade empírica do espaço (no que se refere a toda a experiência exterior possível) e, não obstante, a sua idealidade transcendental, ou seja, que o espaço nada é, se abandonarmos a condição de possibilidade de toda a experiência e o considerarmos com algo que sirva de fundamento das coisas em si. (KANT, 2001, pp. 68-69). Uma análise de tal crítica, expondo suas diferenças e sobretudo proximidades, se propõe como um relevante programa de pesquisa a ser realizado, mas infelizmente não é o interesse deste presente trabalho. Em suma, "realidade empírica" do espaço significa realidade aparente do espaço: nós vemos o espaço como algo situado fora do nosso corpo, mas esse "fora" é uma projeção subjetiva do nosso eu. O espaço em si é impossível para ambos os autores, sendo assim a crítica kantiana baseada numa série de paralogismos e ambiguidades de terminologia.

${ }^{11}$ Tal como Karl Popper in A Lógica da Pesquisa Científica.
} 
ao "segundo" Wittgenstein e Wilfrid Sellars (cf. BERMAN, 2000; SELLARS, 2003) 12, acreditando que os dados dos sentidos se configuram em si numa linguagem pura dotada de significação, embora incomunicável. Um problema que podemos salientar em sua teoria do conhecimento é que um dos seus pressupostos não foi demonstrado, a saber, o de que uma ideia somente se assemelha a outra ideia, embora ele possa ser derivado do seu esse est percipi, mas, neste caso, a argumentação torna-se circular. No mais, sua argumentação é clara e o autor busca convencer através de um claro entendimento e encadeamento lógico, sem a tentativa de rebuscar o conteúdo com termos obscuros. Aliás, como ele deixa expresso logo no início de sua obra, a obscuridade ou vagueza de termos é um defeito que não pode existir na filosofia.

Como já fora exposto várias vezes, além de ter sido uma grande influência para o desenvolvimento do empirismo posterior, Berkeley também é um autor que nos ajuda a compreender a ciência nos dias de hoje. Trata-se de uma rica filosofia que merece ser lida e valorizada, submetida a um justo julgamento situando-a em seu tempo, além da análise da engenhosidade dos argumentos do filósofo.

Correspondência: Universidade Estadual de Londrina - UEL. Centro de Letras e Ciências Humanas. Departamento de Filosofia. Rodovia Celso Garcia Cid, Pr 445 Km 380. Campus Universitário. Londrina - PR - Brasil. CEP 86.057-970. E-mail: gabrielchi@hotmail.com / E-mail: pedropizzutti@gmail.com.

Apoio financeiro: CNPq.

Conflito de interesses: Nenhum.

Todos os autores leram e aprovam a versão final submetida à revista Em curso.

\footnotetext{
${ }^{12}$ Quanto a isso, o professor David Berman faz uma justa ponderação e inclusive levanta um possível caminho de defesa de Berkeley, alegando que "um berkeliano poderia apontar para crianças ainda não falantes, as quais - adaptando a descrição dada por Berkeley na Introdução § 14 - parecem capazes de brincar inteligentemente e fazer julgamentos mentais sobre seus chocalhos e seus doces, sem o uso da linguagem" (BERMAN, 2000, p. 51).
} 


\section{REFERÊNCIAS}

BERKELEY, G. Principles of human knowledge; and, Three dialogues between Hylas and Philonous. London: Penguin Books, 1988.

BERKELEY, G. Obras filosóficas. Tradução, apresentação e notas de Jaimir Conte. São Paulo: Ed. UNESP, 2010.

BERKELEY, G. De Motu. Tradução de Marcos Rodrigues da Silva. Scientiae Studia, v. 4, n. 1.

FRENCH, S. Ciência: conceitos-chave em filosofia. Tradução de André Klaudat. Porto Alegre: Artmed, 2009.

GHINS, M. Uma introdução à metafísica da natureza: Representação, realismo e leis científicas. Tradução de Eduardo Salles O. Barra e Ronei Clécio Mocellin. Curitiba: Ed. UFPR, 2013.

HUME, D. Investigação acerca do entendimento humano. Tradução de Anoar Aiex. São Paulo: Nova Cultural, 1999.

KANT, I. Crítica da Razão Pura. Tradução de Manuela P. dos Santos e Alexandre F. Morujão. Lisboa: Fundação Calouste Gulbenkian, 2001.

LAUDAN, L. O progresso e seus problemas. Tradução de Roberto Leal Ferreira. São Paulo: Ed. UNESP, 2010. POPPER, K. A Lógica da Pesquisa Científica. Tradução de Leônidas Hegenberg e Octanny S. da Mota. São Paulo: Cultrix, 2013.

RUSSELL, B. História da Filosofia Ocidental. Tradução de Brenno Silveira. São Paulo: Companhia Editora Nacional, 1957.

SILVA, M. Instrumentalismo e explicação científica no de motu de berkeley. Scientiae Studia, vol. 4, n. 1, 2006.

SILVA, M. O anti-abstracionismo de Berkeley como um problema para a distinção observável/ inobservável. Problemata, vol. 5, n.1, 2014.

STRATHERN, P. Berkeley em 90 minutos. Tradução de Cassio Boechat. Rio de Janeiro: Zahar Editora, 2003.

THAGARD, P. The Conceptual Structure of the Chemical Revolution. Philosophy of Science, vol. 57, no. 2, 1990.

VAN FRAASSEN, Bas. A imagem científica. Tradução de Luiz Henrique de Araújo Dutra. São Paulo: Ed. UNESP, 2007. 